\title{
Haematuria in rheumatoid arthritis: a follow up study
}

\author{
C A KELLY, ${ }^{1}$ P MOONEY, ${ }^{1}$ L D HORDON, ${ }^{2}$ AND I D GRIFFITHS ${ }^{1}$
}

From the ${ }^{1}$ Department of Rheumatology, Freeman Hospital, Newcastle upon Tyne; and the ${ }^{2}$ Rheumatology Department, Leeds General Infirmary

SUMMARY Twenty one patients with seropositive rheumatoid arthritis and previously documented isolated haematuria were recalled at a median $7 \cdot 7$ years (range 3-12) after initial investigation. Eighteen subjects had previously undergone renal biopsy, which had shown mesangial glomerulonephritis in all but four cases. Renal function was found to have remained normal in all patients with previous mesangial changes despite the presence of persistent haematuria in most cases.

Key words: mesangial glomerulonephritis, creatinine, second line drugs.

Although mesangial changes are well recognised in patients receiving treatment with gold or D-penicillamine, ${ }^{12}$ the presence of a similar renal lesion relating to rheumatoid arthritis itself has proved debatable. ${ }^{34}$ In a previous paper we described changes of mesangial glomerulonephritis in most renal biopsy specimens obtained from patients with rheumatoid arthritis and persistent haematuria, ${ }^{5}$ most of whom had never received second line drugs. The prognosis for the patients with established mesangial glomerulonephritis and rheumatoid arthritis appeared to be good as none of them showed a reduction in creatinine clearance at the time of initial diagnosis. This follow up study re-examines renal function in these patients nearly eight years after initial investigation for haematuria.

\section{Patients and methods}

Twenty four patients with classical or definite rheumatoid arthritis ${ }^{6}$ and recurrent microscopic haematuria not due to a local cause in the collecting system had been identified. Percutaneous renal biopsy had been performed in all but three patients, in whom red cell casts were not detected.

We attempted to review all 24 patients but were unable to trace three. Of the remaining 21 , one patient had died from renal failure, while another had become anuric 24 months after renal biopsy and was receiving dialysis.

In the remaining 19 patients urine was tested for the presence of blood and protein (Labstix; Ames Diagnostics) and examined under high power microscopy for granular and red cell casts. A midstream urine specimen was cultured in all cases where blood or protein was detected. Blood pressure was measured and blood taken for measurement of erythrocyte sedimentation rate, rheumatoid factor titres, and serum creatinine. Any changes in treatment since the time of initial investigation were recorded. No patient had a repeat renal biopsy.

\section{Results}

The median time of follow up since renal biopsy was $7 \cdot 7$ years (range 3-12). Table 1 shows the results. In the two patients who developed severe renal failure renal impairment had been detected at the time of biopsy and both had significant histological changes: focal crescentic glomerulonephritis in one case and severe ischaemic changes, probably unrelated to rheumatoid arthritis, in the other. In the remaining 19 cases renal biopsy had been undertaken in 16 and had shown features of mesangial glomerulonephritis in all but two. Within this group of 19 patients the median value of serum creatinine was $76 \mu \mathrm{mol} / 1$ (range 49-103 $\mu \mathrm{mol} /$ ) compared with a median of $70 \mu \mathrm{mol} / 1$ (range $48-109 \mu \mathrm{mol} / \mathrm{l}$ ) at the time of the earlier study. Twelve had persistent microscopic haematuria while two had mild proteinuria $(<0.5 \mathrm{~g} / \mathrm{l})$, and a further five had no abnormality on Labstix testing. Granular urinary casts were not seen in any patient. One patient with haematuria and one with proteinuria had urinary tract infections, but these findings persisted after eradication of the infection. 
Table 1 Correlation of histological features on renal biopsy with findings on review

\begin{tabular}{|c|c|c|c|c|c|}
\hline \multirow{2}{*}{$\begin{array}{l}\text { Initial biopsy } \\
\text { findings }\end{array}$} & \multirow{2}{*}{$\begin{array}{l}\text { Number of } \\
\text { patients }\end{array}$} & \multicolumn{2}{|c|}{ Creatinine ( } & \multirow{2}{*}{$\begin{array}{l}\text { Haematuria } \\
\text { at review }\end{array}$} & \multirow{2}{*}{$\begin{array}{l}\text { Hypertension } \\
\text { at review }\end{array}$} \\
\hline & & Initial & Review & & \\
\hline Mesangial GN† & 14 & $\begin{array}{l}70 \\
(48-109)^{*}\end{array}$ & $\begin{array}{l}76 \\
(49-103)\end{array}$ & 9 & 1 \\
\hline Membranous GN & 1 & 76 & 89 & 1 & 1 \\
\hline Interstitial $\mathrm{GN}$ & 1 & 100 & 88 & 1 & 1 \\
\hline Crescentic GN & 1 & 240 & Died & & \\
\hline Arteriosclerosis & 1 & 168 & Dialysis & & \\
\hline
\end{tabular}

*Values are median (range).

$+\mathrm{GN}=$ glomerulonephritis.

Blood pressure was normal in 16 patients with normal renal function, but hypertension (diastolic blood pressure $>90 \mathrm{mmHg}$ ) was noted in three cases. One of these patients had had features of a membranous nephropathy, another of interstitial disease, and only one had had a mesangial glomerulonephritis. Persisting haematuria was noted in each of these three patients. There was no association between the development of hypertension and either disease duration or disease activity as assessed by erythrocyte sedimentation rate and rheumatoid factor titre.

All but two of the patients reviewed in this study had continued to take a regular non-steroidal antiinflammatory agent, one exception being the patient receiving renal dialysis. Only seven of them had ever taken either gold or penicillamine for more than one month, however, with only two of these continuing treatment up to the time of review. One of these patients had started gold after renal biopsy was performed, while the other had been taking penicillamine for nine years, with no effect on renal function.

\section{Discussion}

Although a variety of renal lesions have been described in patients with rheumatoid arthritis receiving gold or penicillamine, both mesangial ${ }^{4}$ and membranous ${ }^{7}$ glomerulonephritis have been reported in those who have never received second line agents. Hence our finding that haematuria did not relate to gold or penicillamine treatment suggests that the renal pathology relates to rheumatoid arthritis rather than to its treatment.
Creatinine clearance was already reduced at the time of renal biopsy in both patients who developed ${ }^{\omega}$ renal failure during the follow up period. Addition-ally, two of the three patients with hypertension had ${ }^{-}$ renal pathology other than mesangial glomerulo- $\Phi$

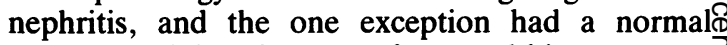
serum creatinine six years after renal biopsy.

Treatment with a wide variety of anti-inflammatory@ drugs appeared to influence neither renal function $\overrightarrow{0}$ nor blood pressure in our patients with an establish doo mesangial glomerulonephritis. This suggests that such agents may safely be continued under theo circumstances.

The pressure of mesangial glomerulonephritis in patients with rheumatoid arthritis does not appearo to be associated with deterioration in renal function despite the persistence of haematuria in most cases.

\section{References}

1 Blackwell M R, Hall C L, Tribe C R, Bacon P A. Gold induced nephropathy. Ann Rheum Dis 1981; 40: 525.

2 Tornroth T S, Skrivars B. Gold nephropathy: prototype of membranous glomerulonephritis. Am J Pathol 1974; 75 573-84.

3 Burry H. Renal disorders in rheumatoid arthritis. Rheumatology and Physical Medicine 1971; 11: 2-9.

4 Lee T C, Dushkin J, Eyring E J, Engelman E P, Hopper J Renal lesions associated with gold therapy: light and electrono microscope studies. Arthritis Rheum 1965; 8: 1-13.

5 Hordon L, Sellars L, Morley A, Wilkinson R, Thompson M Griffiths I D. Haematuria in rheumatoid arthritis: an association with mesangial glomerulonephritis. Ann Rheum Dis 1984 o
43: 440-3.

6 Ropes M W, Bennett G A, Cobb S, Jacox R, Jessar R A Revision of the diagnostic criteria for rheumatoid arthritis. Ann Rheum Dis 1959; 18: 49-54.

7 Honkanen E, Tornroth T, Petterson E, Skrivars P. Membranous glomerulonephritis in rheumatoid arthritis not related to gold of D-penicillamine therapy. Clin Nephrol 1987; 27 : 87-93. 